\title{
Singing Sand Dunes: The Spontaneous Acoustic Emission from Granular Shear Flow
}

\author{
Kishore Dutta \\ Department of Physics, Handique Girls College, Guwahati, India \\ Email: kdkishore77@gmail.com
}

Received 19 August 2015; accepted 4 September 2015; published 10 September 2015

Copyright (C) 2015 by author and OALib.

This work is licensed under the Creative Commons Attribution International License (CC BY). http://creativecommons.org/licenses/by/4.0/

(c) (i) Open Access

\begin{abstract}
One of the highly striking yet poorly understood natural phenomena is the song of dunes. Some sand dunes in deserts have a peculiar ability to emit a loud persistent sound with a characteristic audible low-frequency ( $\approx 75-105 \mathrm{~Hz}$ ), which sometimes can be heard up to $10 \mathrm{~km}$ away. Scientific investigations suggest that the sustained low-frequency sound of sand dunes that resembles a pure note from a musical instrument is due to the synchronized motion of well-sorted dry sand grains when they spontaneously avalanche under gravity. This article describes the underlying mechanism for sustained sound emission in singing sand dunes in light of the recent physical experiments.
\end{abstract}

Keywords

Avalanche, Granular Shear Flow, Synchronized Motion, Surface Elastic Wave, Singing Sand

Subject Areas: Dynamical System, Modern Physics

\section{Introduction}

The desert spirits can do amazing and incredible things. Even in the daytime their voices can sometimes be heard, or there is a clash of arms, a roll of drums or the sound of different musical instruments. For these reasons, travelers go in large numbers and stay close to one another.

- Marco Polo (1295)

In 13th century, the Venetian explorer Polo [1] on his journey through the Gobi desert witnessed strange noises which he ascribed to the voices of evil spirits and goblins. He wrote that the singing sands "at times fill the air with the sounds of all kinds of musical instruments, and also of drums and the clash of arms". Many explorers including Polo, Doughty [2], Bagnold [3], the Mughal emperor Babur [4], the viceroy of India Lord Curzon [4], and others [5] [6] have been mystified by the booming sounds of the desert. The legends and mystical beauty of singing sand dunes have taken a special place in many poetry, art, desert folklore, and docu- 
mentary for centuries.

Scientists started to unravel the mystery of sound generation in sands by the end of the 19th century [7]-[16]. Recently, through a number of indigenous experiments and direct field observations [17], physicists strive very hard for understanding the underlying dynamical mechanism of singing dunes [18]-[22]. Their in-depth investigations are able to provide a physical picture of singing dunes on the basis of the dynamics of granular flow. It is interesting and, at the same time, quite hard to speak about the song of dunes as the singing mechanism is not as usual. Rather than entering the mathematical details, in this article, we make an attempt to visualize the physical insight on the basis of the available standard scientific observations and explanations.

\section{Sand Grains under Shear}

Sand is a granular material with astonishing physical behavior. While pouring freely under gravity, sands can act like a fluid with viscosity. The falling sand grains form a heap with rigidity, a characteristic of a solid. The windswept sand grains, temporarily suspended in the air like a gas, can travel long distances. There are some strange sand beaches in Japan (Kotobikihama beach [23]), Great Britain (the Isle of Eigg [24]), Canada (Basin Head, Prince Edward Island), and the United States (Barking sands of Kaua'i, Hawai [25]) which emit high frequency $(\sim 1 \mathrm{KHz})$ sound when walked upon. While walking, the sand is displaced quickly underfoot and emits a high frequency squeak or whistle of short duration. In order to explain why some sands sing, scientists by the end of the 19th century, proposed explanation based on the characteristics of the grains. It was found that not all sands are musical; the singing sands are composed of dry (free of humidity), rounded, and polished (free of dust and pollution) grains having a very narrow size distribution [7] [9] [10] [13] [15] [24] [26]. CarusWilson [7] attributed the sound to friction between grains while Bolton and Julien [8] proposed the generation of sound in terms of an air film acting as a cushion capable of vibration. Poynting and Thompson [11] [12], on the other hand, pointed out that sound is produced by the relative motion between grains and that the frequency $f$ scales with the shear velocity $v$ and the characteristic length scale (the grain size) $d$, as $f \approx v / d$. Compressing sand grains by a pestle, Hidaka et al. [16] observed discrete shear bands and attributed it to the frictional properties of the sand. The frequency $\left(f_{s q}\right)$ of the whistling on this compressed sand was found to depend on the width of the shear band $\delta h$, the penetration speed of the pestle $v_{p}$, and the total number of shear band $n$, as

$$
f_{s q}=\frac{n v_{p}}{\delta h} .
$$

Depending on the penetration speed $v_{p}$, the squeaking frequency varies from 250 to $355 \mathrm{~Hz}$. Laboratory experiments [27] also recorded frequencies ranging from 340 to $700 \mathrm{~Hz}$ while exciting whistling sand with a pestle in a glass pot. Nevertheless, the "squeaking" sound on sand beaches, consisting of short acoustic bursts, differ fundamentally from the sustained acoustic emission from the singing dunes [28] [29]. In the following section, we shall discuss briefly the morphology of sand dunes that might help the reader to follow the subsequent section.

\section{An Overview of Sand Dunes}

In deserts, wind-blown sand is important in shaping the physical scenery. Wind lift grains of sand, which are then blown and bounced forward. The wind piles the sand up to a single summit known as dune (Figure 1). Sands start to cascade down (avalanche) naturally under the influence of gravity when the slope locally exceeds the static friction coefficient $\mu_{s}=\tan \theta_{s}$. In such a case, the gravity overcomes the frictional drag and triggers an avalanche down the surface. For a natural aeolian dune $\theta_{s}$ is around $35^{\circ}$. Across the Earth's dry sand deserts, there are several types of dunes with large slip faces. These dunes are the results of complex physical interactions between wind flow and sand bed. The wind sets the sand grains into motion, controll the sand flux, and construct a characteristic shape of the dune. Alternatively, the shape of the dune determines the velocity field around it and modifies the flow pattern of the wind. The equilibrium between these two processes leads to the selection of shape and dynamics of dunes. Accordingly, dunes are differentiated mainly as barchan (crescent shaped dunes, horn downwind, and the slip face is on the concave side), linear (long, parallel ridges separated by corridors), parabolic (U-shaped with arms pointing downwind and crest pointing upwind), and star dunes (several radially symmetrical arms and slip faces). 


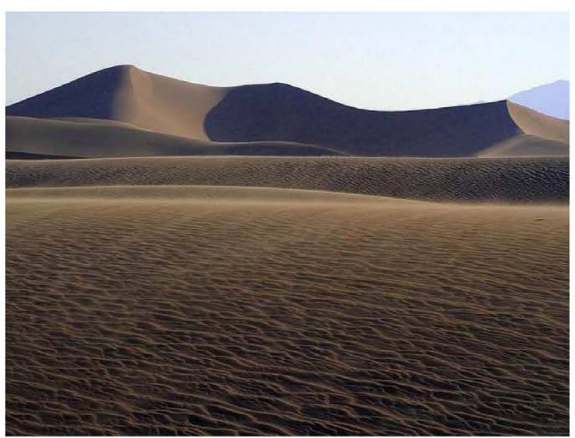

(a)

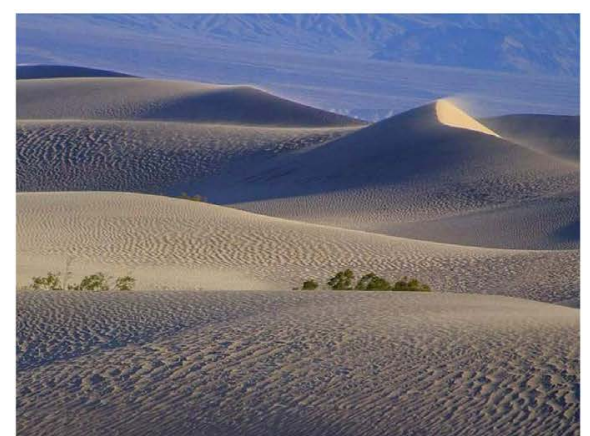

(b)

Figure 1. Enigmatic structure of sand dunes in desert.

The crescent shaped barchans are visually striking enigmatic structures of many deserts [30] [31]. They are formed when the wind blows mainly from one direction [32]. The back of the dune is eroded by the wind; the sand transported in saltation is deposed at the brink, and is redistributed on the slip-face by avalanches. There are very few places in the world that are touched by trade winds driven by oceanic anticyclones. These anticyclones are very stable and the winds are constant and often very strong. The Peruvian and Chilean coasts, coastal Namibia, Atlantic coast of the Sahara, Morocco, Senegal, northern shores of western Australia are some of these regions. Morphologic measurements on these regions show that there is not only a constantly prevailing wind direction but also a smooth ground surface. When the direction of wind is almost constant, these dunes can maintain a nearly invariant shape and size $(3-10 \mathrm{~m})$ for a very long time $(1-30$ years $)$ [3] [6]. In Atlantic Sahara region there are more than 10,000 barchans [32]. They occur singly or in cluster and propagate on solid ground under unidirectional wind. When winds drive sand dunes forward, seif dunes are formed, named after an Arabic word meaning sword. Sometimes advancing dunes bury farmland and to stop their advance, people plant trees and grasses to anchor the sand.

\section{Physics of Singing Sand Dunes}

Many desert sand dunes sing by emitting a persistent, low-frequency harmonious sound, characterized by a dominant audible frequency $(f=70-105 \mathrm{~Hz})$ and several higher harmonics. This acoustic emission that resembles the sound of a drum, can last for several minutes and sometimes can be heard up to $10 \mathrm{~km}$ away. The singing sand dunes are one of the great artistry of Nature captivating human for centuries. This booming sound has been reported on latitudes on both the northern $\left(47^{\circ} \mathrm{N}\right.$ and $\left.19^{\circ} \mathrm{N}\right)$ and the southern hemisphere $\left(19^{\circ} \mathrm{S}\right.$ and $29^{\circ} \mathrm{S}$ ) covering desert climates in the subtropics and the mid-latitudes. Although star dunes are the most common dune type for booming, booming has also been found on barchans [17], on long linear dunes, and on mountains with extended sand drifts.

The singing dunes (Figure 2) emit sound when wind blows over them. However, it is recognized that the harmonic sound is not due to the wind [3]. It is the grain motion during the slumping event or natural avalanche on their slip faces, that causes the sound. This has been proved by creating artificial avalanches in laboratory that exactly have the same acoustic emission. More recently, physicists are interested in this fascinating problem and a lot of interesting experimental results have been accumulated [18]-[20] [22] [33] [34]. Bruno Andreotti [18], one of the pioneer physicists in this field, performed a series of experiments in the Atlantic Sahara (Morocco) covering more than 10,000 barchans and observed that, in the absence of humidity, all the barchans produce sound [17]. Among them, there are three large mega-barchans that can emit sound 350 days per year as they are almost always dry on the surface. Most of the other smaller dunes can emit only a few tens of minutes per year during sunny weather. The wind erodes the back of the dune and accumulates sand at the top of the slip face at the front. When the slope is too large, a spontaneous avalanche nucleates and propagates down the dune, and sound is produced. Andreotti and his group in their experiments with grain size $180 \mu \mathrm{m}$, observed a constant frequency $f$ of $100 \pm 5 \mathrm{~Hz}$ independent of the size of the dune and the location of the avalanche. Recently Douady et al. [19] during their field observations in Morocco, Chile, China, and Oman also observed a frequency range $75-105 \mathrm{~Hz}$ depending on the grain size $(160-340 \mu \mathrm{m})$. 


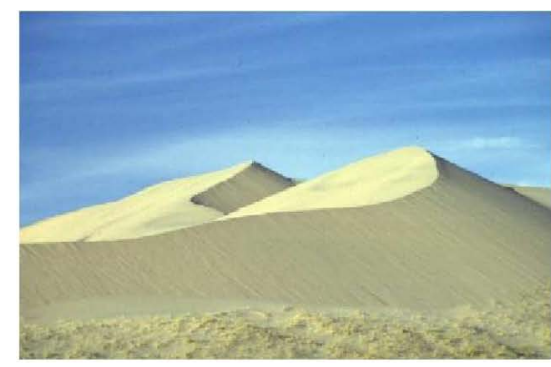

(a)

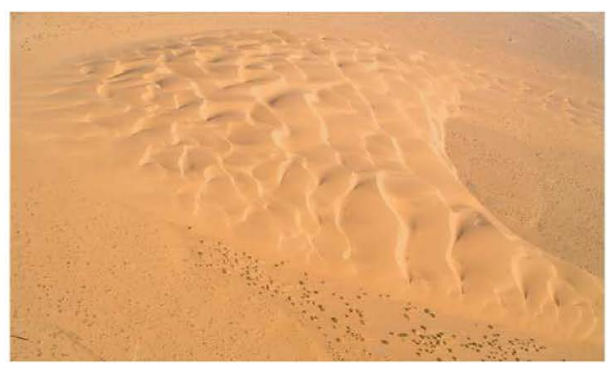

(b)

Figure 2. (a) Kelso dune in California: one of the sound producing barchans; (b) Megabarchan in the Atlantic Sahara.

The above mentioned experimental studies and field observations, mainly aimed at elucidating the underlying physics of the booming sound in sand dunes in terms of the granular shear flow, can be summarized as follows. The well-sorted and rounded grains (having the same size $d$ ) of singing dunes can all share the same motion in the avalanche, with each grain passing over lower grains and hitting them at a rate $\Gamma$. During this process, the free surface of the sand bed moves up and down. Laboratory experiments [18] revealed that normal acceleration of the free surface is approximately in phase with the pressure time derivative and it is exactly the same for a loudspeaker whose membrane is covered by sand. Thus the free surface of the sand bed during avalanche vibrates like a membrane of a loudspeaker and excite elastic waves at the flowing layer. At the same time, a grain of size $d$ inside the avalanche moves at a mean velocity $\Gamma d$ with respect to the grains beneath it. These collisions, at a mean frequency $\Gamma$, further excite the surface elastic waves. If the whole sand layer oscillates at a frequency $f$ close to $\Gamma$, it induces a further force that oscillates in time at frequency $f$. This feedback mechanism tends to synchronize the motion of the grain with the oscillation and a number of grains move in synchrony. Eventually, the resultant surface elastic waves exist both inside and outside the avalanche and are localized at few centimeters below the surface, just like Rayleigh waves [35]. The vibration of these resultant elastic waves produce the coherent acoustic emission in the air and the frequency $f$ of the emitted sound is controlled by the collision rate $\Gamma$ of the grains inside the avalanche.

In granular flow, the rate $\Gamma$ at which grains jump over their neighbours and make collisions, is a measure of the velocity gradient (or shear). Andreotti and his group [18] found that the velocity gradient $\Gamma$ is independent of the flowing depth $H$ and is precisely equal to the spontaneous frequency $f$ of acoustic emission. Thus it suggests that the acoustic emission of harmonic sound is induced by coherent elastic waves, localized in surface whose frequency $f$ is set by the shear rate $\Gamma$ of the shear band separating the avalanche from the static part of the dune. In other words, the vibration of the sand bed tends to synchronize the collisions, which themselves excite this vibration.

The above experimental results clearly indicate that the sound emitted in the air is neither due to any resonant condition nor due directly to the avalanche. It is the coherent vibration of the free surface that causes such a booming sound whose frequency depends on the size of the grains. For a gravity induced flow, $f$ is roughly equal to

$$
f \approx 0.4 \sqrt{\frac{g}{d}},
$$

where $g$ is the acceleration due to gravity and $d$ the grain size. The upper bound of the sound level $105 \mathrm{~dB}$ corresponds to the amplitude of vibration for which the normal acceleration of the free surface just balances gravity, i.e., whenever the grains start taking off the surface. In fact, the scaling of the frequency $f \sim d^{-1 / 2}$ was approximately verified by several researchers [26] [28] in the narrow range of diameters $d$ [from $180 \mu \mathrm{m}$ $(f=100 \mathrm{~Hz})$ to $380 \mu \mathrm{m}(f=66 \mathrm{~Hz})]$ of sounding grains across the world. This relation suggest that in a natural avalanche, the shear rate $\Gamma$ is directly proportional to the acceleration due to gravity $g$. Eventually, while one quickly pushes a small avalanche by hand, or releases a large quantity of sand on a flat surface, the inertial effects add to gravity and modify the shear rate, which in turn modifies the shock frequency. This correspond to what is observed as squeaking sound with frequency of the order of $1 \mathrm{KHz}$ as discussed earlier. Remarkably, this effect has been verified recently in laboratory [19] by plugging a blade at different depths into 
a prepared crest of singing sand and rotating by a motor at different velocities. With this set-up, allowing independent control of both the shearing velocity and the mass of sheared sand, sustained sounds of constant and well-defined frequencies are obtained in a wide frequency range. By two controlled experiments in laboratory and in field, Douady et al. [19] further suggested that the sound is produced because moving grains synchronize their motions due to a coupling inside the sheared layer and, the frequency is only controlled by the mean shear applied to the grains.

Although the physicists proposed a number of theories based on the direct observations and laboratory experiments as discussed above, there are a number of controversial issues regarding the origin of sustained lowfrequency sound in sand dunes. Among them, the description based on the resonance condition faced a serious debate in recent years. Some physicists believe that the booming sound in sand dunes originates due to resonance inside the dune just like the origin of musical sounds in an wind instrument [21] [36] [37].

While singing, various harmonics are produced by our vocal physiological mechanism. The articulatory apparatus (the lips, jaw, tongue, and velum) controls the air flow and modulates the air pressure. The rapid air flow reduces the air pressure which attracts the vocal folds (often referred, non-technically, as vocal cords) to each other and thus reduces the cross-section for the air flow. As a result of the smaller cross section, the airflow is reduced, the pressure rises again, and the vocal folds open up again. This leads to larger airflow, and the cycle starts again. It is this periodic vibration of the folds whose rate gives the pitch of the sound. Our vocal tract is a cavity between the vocal folds and the lips, and acts as a resonator that spectrally shapes the periodic input, like the cavity of a musical wind instrument. When we produce particular vowels, we are essentially changing the shape of the vocal tract cavity by placing the tongue and other articulators in particular positions. Thus, under certain conditions, human speech production can be approximated as an excitation source filtered by an acoustic tube with resonances, much like resonances in organ pipes [38]. As we know, musical sounds can also be set up by oscillating strings (guitar, piano, violin), membranes (kettledrum, snare drum), air columns (flute, pipe organ), wooden blocks or steel bars (marimba, xylophone), and many other oscillating bodies. Most common instruments involve more than a single oscillating part. In reed instruments, such as the clarinet, the reed has the role of the vocal folds, and the pipe and the mechanisms have the role of the mouth. In brass instruments, such as the trombone, the lips play the role of the reed. In airflow instruments, such as the flute, the airflow is deflected at the sound-producing edge by the sound itself. Does a booming sand dune follow a similar mechanism to create its spontaneous harmonic sound?

It is believed that the dry surface layer of the dune constitutes a resonant cavity [21] [36] [37]. The standing mode associated with this layer is a passive resonance because energy does not propagate and get stored in the cavity. Thus the avalanche must be considered a source of noise which injects energy into the static dune over a broad frequency band. The dune would behave as a passive filter which selectively reinforces the frequency $f_{R}$ at which vibration amplitude becomes maximum. If this is the case, then the booming frequency $f$ should match with the resonant frequency $f_{R}$. The experiments on Atlantic Sahara [20], however, indicate a measurable difference between the resonance frequency and booming frequency. In addition to this inconsistency, the indigenous laboratory experiments performed by Douady et al. [19] suggest that the low-frequency booming sound can be produced without a dune and, therefore, the sound is not due to the resonance inside the dune. This is in marked contrast to the believe that the origin of sound in singing dunes is the resonance in the dune as in musical instruments.

\section{Conclusion}

In this article, based on a number of existing standard scientific field observations and laboratory experiments, we describe the underlying physical principles for the singing sand dunes without any mathematical details. Indeed, the dynamics of granular surface flow during avalanche is governed by a set of nonlinear dynamical equations describing the nonlinear coupling between a moving layer and an erodible bed of static grains. In addition, fluctuations and inhomogeneities on the scale of the granular particles strongly influence their behavior. Thus, a detail numerical simulation is needed to unravel the underlying dynamical behavior of the granular mater, particularly the spontaneous acoustic emission induced by a granular shear flow. In a fluid flow in the presence of shear, the coupling between the flow and density fluctuations arises due to the density dependence of viscosity [39]. This violation of the incompressibility condition may be generalized to any granular matter where, due to the friction of the grains, the compressibility of the material cannot be neglected at low Mach number, as it is coupled to the shear flow. The friction between the granular flow and the static part of the dune 
is responsible for an exponential growth of elastic waves. Inside any thick interface of a granular matter, shear stress increases with pressure and acoustic modes get coupled to the mean flow. Consequently, the acoustic modes can be amplified when reflected by the diffusive shear band. Another interesting feature observed in such nonlinear dynamical systems is the mode-locking [18]. It consists of the resonant response to an external periodic force that occurs when a characteristic frequency of the driven system matches or locks onto the driving frequency. How the plastic deformation (shear band) and the elastic compression (acoustics) of the granular material lead to the synchronization of the grain collision and how it is related to the mode-locking are interesting problems to study. The complex behavior of granular shear flow, in fact, poses a formidable challenge for theoretical descriptions and numerical approaches that aim at a fundamental analysis and interpretation of the underlying physical mechanisms at work in the song of dunes. However, we hope that the eternal beauty and musical magic of the singing sand dunes will deserve to provide wildly enthusiastic ingredient to human endeavor in uncovering the century-old mystery.

\section{References}

[1] Polo, M. (1938) The Description of the World. Edited by Moule, A.C. and Pelliot, P.G., Routledge, London. Available Online; See Ref. [17].

[2] Doughty, C.M. (1888) Travels in Arabia Deserta. Vol. 1, Cambridge University Press, Cambridge.

[3] Bagnold, R.A. (1941) The Physics of Blown Sand and Desert Dunes. Chapman and Hall, London.

[4] Curzon, G.N. (1923) Tales of Travel. Hodder and Stoughton, London (Reprinted: Century, London, 1988).

[5] Pye, K. and Tsoar, H. (1990) Aeolian Sand and Sand Dunes. Unwin Hyman, London. http://dx.doi.org/10.1007/978-94-011-5986-9

[6] Cooke, R., Warren, A. and Goudie, A. (1993) Desert Geomorphology. UCL Press, London.

[7] Carus-Wilson, C. (1888) Musical Sands. Proceedings of the Bournemouth Natural Science Society, 2, 1-20.

[8] Bolton, H.C. and Julien, A.A. (1888) The True Cause of Sonorousness in Sand. Transactions of the New York Academy of Sciences, 8, 9-10.

[9] Carus-Wilson, C. (1891) The Production of Musical Notes from Non-Musical Sands. Nature (London), 44, $322-323$. http://dx.doi.org/10.1038/044322a0

[10] Carus-Wilson, C. (1908) Musical Sands. Nature (London), 77, 222. http://dx.doi.org/10.1038/077222c0

[11] Poynting, J.H. (1908) Musical Sands. Nature, 77, 248. http://dx.doi.org/10.1038/077248b0

[12] Poynting, J.H. and Thomson, J.J. (1909) A Text-Book of Physics, 2 Sound. Charles Griffin \& Co, London.

[13] Takahara, H. (1973) Sounding Mechanism of Singing Sand. Journal of the Acoustical Society of America, 53, 634-639. http://dx.doi.org/10.1121/1.1913367

[14] Ledoux, A.E. (1920) Singing Sands. Science, 51, 462-464. http://dx.doi.org/10.1126/science.51.1323.462-a

[15] Haff, P. (1986) Booming Dunes. American Scientist, 74, 376-381.

[16] Hidaka, J., Miwa, S. and Makina, K. (1988) Mechanism of Generation of Sound in Shear Flow of Granular Materials. International Chemical Engineering, 28, 99-107.

[17] Records of the Song of Dunes May Be Heard at http://www.pmmh.espci.fr/andreotti/SongOfdunes.html

[18] Andreotti, B. (2004) The Song of Dunes as a Wave-Particle Mode Locking. Physical Review Letters, 93, Article ID: 238001. http://dx.doi.org/10.1103/PhysRevLett.93.238001

[19] Douady, S., Manning, A., Hersen, P., Elbelrhiti, H., Protière, S., Daerr, A. and Kabbachi, B. (2006) Song of the Dunes as a Self-Synchronized Instrument. Physical Review Letters, 97, Article ID: 018002. http://dx.doi.org/10.1103/PhysRevLett.97.018002

[20] Bonneau, L., Andreotti, B. and Clement, E. (2007) Surface Elastic Waves in Granular Media under Gravity and Their Relation to Booming Avalanches. Physical Review E, 75, Article ID: 016602. http://dx.doi.org/10.1103/PhysRevE.75.016602

[21] Vriend, N., Hunt, M., Clayton, R., Brennen, C., Brantley, K. and RuizAngulo, A. (2007) Solving the Mystery of Booming Sand Dunes. Geophysical Research Letters, 34, Article ID: L16306. http://dx.doi.org/10.1029/2007gl030276

[22] Andreotti, B. and Bonneau, L. (2009) Booming Dune Instability. Physical Review Letters, 103, Article ID: 238001. http://dx.doi.org/10.1103/PhysRevLett.103.238001

[23] Miwa, S. and Okazaki, T. (1995) Sound of Booming Dunes in China and America. Sand Dune Research (Japanese), 42, 20 . 
[24] Ridgway, K. and Scotton, J. (1973) Whistling Sand Beaches in the British Isles. Sedimentology, 20, 263-279. http://dx.doi.org/10.1111/j.1365-3091.1973.tb02049.x

[25] Bolton, H. (1889) Researches on Musical Sand in the Hawaiian Islands and in California. Transactions of the New York Academy of Sciences, 10, 28-35.

[26] Lindsay, J.F., Criswell, D.R., Criswell, T.L. and Criswell, B.S. (1976) Sound-Producing Dune and Beach Sands. Geological Society of America Bulletin, 87, 463-473. http://dx.doi.org/10.1130/0016-7606(1976)87<463:SDABS>2.0.CO;2

[27] Miwa, S., Okazaki, T. and Kimura, M. (1995) Evaluation of the Sound-Producing Properties of Singing Sand. The Science and Engineering Review of Doshisha University, 36, 67-76.

[28] Nori, F., Sholtz, P. and Bretz, M. (1997) Booming Sand. Scientific American, 277, 84-89. http://dx.doi.org/10.1038/scientificamerican0997-84

[29] Sholtz, P., Bretz, M. and Nori, F. (1997) Sound Producing Sand Avalanches. Contemporary Physics, 38, $329-342$. http://dx.doi.org/10.1080/001075197182306

[30] Hersen, P., Douady, S. and Andreotti, B. (2002) Relevant Length Scale of Brachan Dunes. Physical Review Letters, 89, Article ID: 264301. http://dx.doi.org/10.1103/PhysRevLett.89.264301

[31] Worman, S.L., Murray, A.B., Littlewood, R., Andreotti, B. and Claudin, P. (2013) Modeling Emergent Large-Scale Structures of Barchan Dune Fields. Geology, 41, 1059-1062. http://dx.doi.org/10.1130/G34482.1

[32] Elbelrhiti, H., Andreotti, B. and Claudin, P. (2008) Barchan Dune Corridors: Field Characterization and Investigation of Control Parameters. Journal of Geophysical Research, 113, Article ID: F02S15. http://dx.doi.org/10.1029/2007jf000767

[33] Andreotti, B., Bonneau, L. and Clément, E. (2008) Comment on Solving the Mystery of Booming Sand Dunes. Geophysical Research Letters, 35, Article ID: L08306. http://dx.doi.org/10.1029/2007GL032509

[34] Andreotti, B. (2012) Sonic Sands. Reports on Progress in Physics, 75, Article ID: 026602. http://dx.doi.org/10.1088/0034-4885/75/2/026602

[35] Landau, L. and Lifshitz, E. (1959) Theory of Elasticity. Pergamon Press, London.

[36] Vriend, N., Hunt, M., Clayton, R., Brennen, C., Brantley, K. and RuizAngulo, A. (2008) Reply to Comment on Solving the Mystery of Booming Sand Dunes. Geophysical Research Letters, 35, Article ID: L08307. http://dx.doi.org/10.1029/2008GL033202

[37] Hunt, M. and Vriend, N. (2010) Booming Sand Dunes. Annual Review of Earth and Planetary Sciences, 38, $281-301$. http://dx.doi.org/10.1146/annurev-earth-040809-152336

[38] Flanagan, J.L. (1972) Speech Analysis, Synthesis, and Perception. Second Edition, Springer-Verlag, New York. http://dx.doi.org/10.1007/978-3-662-01562-9

[39] Furukawa, A. and Tanaka, H. (2006) Violation of the Incompressibility of Liquid by Simple Shear Flow. Nature, 443, 434-438. http://dx.doi.org/10.1038/nature05119 